\title{
The comprehensive frailty assessment instrument: Development, validity and reliability
}

\author{
Nico De Witte, RN, MSc ${ }^{a, b, *}$, Robbert Gobbens, PhD, RN, MSc ${ }^{c, d}$, Liesbeth De Donder, PhD, MSc ${ }^{b}$, \\ Sarah Dury, MSc ${ }^{b}$, Tine Buffel, PhD, MSc ${ }^{b}$, Jos Schols, MD, PhD e,f, Dominique Verté, PhD, RN, MSc ${ }^{\text {b }}$

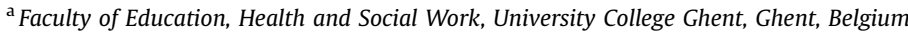 \\ ${ }^{\mathrm{b}}$ Faculty of Psychology and Educational Sciences, Vrije Universiteit Brussel, Brussels, Belgium \\ ${ }^{\mathrm{c}}$ Rotterdam University of Applied Sciences, Rotterdam, The Netherlands \\ ${ }^{\mathrm{d}}$ Department of Tranzo, Scientific Center for Care and Welfare, Tilburg University, Tilburg, The Netherlands \\ e Department of General Practice, CAPHRI School for Public Health and Primary Care, Maastricht University, The Netherlands \\ ${ }^{\mathrm{f}}$ Department of Health Services Research, CAPHRI School for Public Health and Primary Care, Maastricht University, The Netherlands
}

\section{A R T I C L E I N F O}

\section{Article history:}

Received 18 October 2012

Received in revised form

6 March 2013

Accepted 11 March 2013

Available online 19 April 2013

\section{Keywords:}

Frailty

Older persons

Elderly

Validation study

Community

\begin{abstract}
A B S T R A C T
Population aging forces governments to change their policy on elderly care. Older people, even if they are frail and disabled, are motivated to stay in their own homes and environment for as long as possible. Consequently, the early detection of frail older persons is appropriate to avoid adverse outcomes. Several instruments to detect frailty exist, but none use environmental indicators. This study addresses the development and psychometric properties of the Comprehensive Frailty Assessment Instrument (CFAI). This new self-reporting instrument includes physical, psychological, social and environmental domains. The CFAI showed good fit indices and a high reliability. The underlying structure of the CFAI demonstrates the multidisciplinary nature of frailty. Using the CFAI can stimulate nurses and other community healthcare providers toward a more holistic approach of frailty and can guide them to take appropriate interventions to prevent adverse outcomes such as disabilities or hospitalization.
\end{abstract}

(c) 2013 Mosby, Inc. All rights reserved.

\section{Introduction}

Population aging, a phenomenon in which the distribution of a country's population shifts toward older ages, is affecting all Western societies. ${ }^{1}$ To cope with the challenges of a rapidly aging population, several governments have substantially changed their policies on elderly care. Older people, even if they are frail and disabled, are motivated to stay in their own homes and environment for as long as possible. As a consequence, the early detection of frail community-dwelling older persons becomes a significant issue. Several instruments for detection exist, but most have a biomedical emphasis. In most cases, frail older people are detected in clinical settings by screening biomedical indicators (e.g., Fried et $\mathrm{al}^{2}$ ). However, some efforts have been made to broaden the concept by adding psychological ${ }^{3}$ and social indicators ${ }^{4}$ or by using these detection instruments in other settings. ${ }^{5}$ Indeed, screening all community-dwelling older persons clinically for frailty will be impossible, particularly for organizational and financial

\footnotetext{
* Corresponding author. Faculty of Education, Health and Social Work, University College Ghent, Keramiekstraat 80, 9000 Ghent, Belgium. Tel.: +32 93212138.

E-mail address: Nico.dewitte@hogent.be (N. De Witte).
}

consequences. Moreover, by placing the most emphasis on biomedical indicators, the multidimensional character of frailty is disregarded. According to Gobbens et $\mathrm{ll}^{5}{ }^{5}$ an overly narrow definition of frailty, focusing exclusively on physical problems in older people, can lead to the fragmentation of care, thereby jeopardizing the attention for the whole person. Problems such as poor-quality housing, ${ }^{6}$ deprived environments and changing social networks ${ }^{7}$ are neglected. Indeed, while aging, older people will depend highly on the sustainability of their own housing conditions, their environment and their network. ${ }^{8}$ If problems arise within these, older people can also become frail.

Against this background, this article aims to broaden the body of knowledge regarding the concept of frailty by introducing a multidimensional, self-administrated instrument capturing 4 domains of frailty: physical, psychological, social and environmental. To the best of our knowledge, this study is the first to include the environmental domain in the assessment of frailty.

\subsection{A model for measuring frailty in older persons}

As mentioned above, most frailty assessments are dominated by biomedical indicators. Clinicians, for example, use and evaluate 
a wide range of physical problems. This article aims to provide a correction to what has been termed the biomedical domination ${ }^{9}$ by using a multidimensional approach to measure the concept of frailty. This approach is supported by studies showing that when older women are asked how they perceive frailty, most of their answers are linked not only to physical descriptions (e.g., being small, skinny, rather immobile) but also to contextual, social and emotional problems. This observation suggests that older people themselves may have other impressions about frailty than clinicians. ${ }^{10}$ Some scholars therefore include psychological ${ }^{11}$ and social indicators ${ }^{12}$ in addition to the biomedical indicators to measure the concept. Others consider frailty from a live course perspective. Gobbens ${ }^{12}$ model of frailty, for example, expresses relationships between life-course determinants, diseases, frailty and adverse outcomes. Based on this model, the Tilburg Frailty Indicator ${ }^{5}$ was developed, which is an instrument for measuring frailty in community-dwelling older persons in three domains-physical, psychological and social.

The model of Gobbens was used as the basis for the development of the Comprehensive Frailty Assessment Instrument (CFAI), which will be further elaborated in this paper. To meet MarkleReid's and Browne's ${ }^{13}$ guidelines regarding multidimensionality in frailty, Gobbens' model (see Fig. 1), which was based on a model of Bergman, was used and adapted by introducing the environmental domain of frailty in addition to the physical, psychological and social domains. To the best of our knowledge, the environment in which an older individual lives has never been assessed in frailty research. Schröder-Butterfill, ${ }^{6}$ however, indicates that older people can be confronted with environmental challenges, such as poorquality housing. Moreover, as older people spend more time at home and in the vicinity of their homes, they will become highly dependent on the sustainability of their own housing conditions and on the spatial context therein. ${ }^{8}$ The relationship of an aging individual with this spatial context is assumed to be essential and to contribute to an aging individual's quality of life. ${ }^{14}$ Similarly, Wahl et $\mathrm{al}^{15}$ argue that the maintenance of independence in the activities of daily life (ADL) and well-being-related outcomes in later life are also related to the utilization and optimization of environmental resources. Evidence also suggests that the proximity of amenities and services may promote health either directly or indirectly through the possibilities they provide for people to live healthy lives. ${ }^{16}$

In addition to the inclusion of the environmental domain, five other restrictions and requirements were taken into account in the development of the CFAI. First, the new instrument should not be age related as that would suggest a negative and stereotypical view of aging. ${ }^{6}$ Therefore, age was not included as an indicator of frailty but was viewed as a life-course determinant (see Fig. 1). Second, the lived experiences ${ }^{9}$ of older persons themselves were included. Older people were invited to give their judgment about the physical, psychological, social and environmental domains of frailty. Meeting these requirements and expanding the model beyond biomedical variables will withstand Robertson's remarks regarding the medicalization and gerontologization of old age, where aging is reconceptualized as a new 'medical space'. ${ }^{17}$ Third, as the new self-reporting instrument focuses on frailty in older persons, the instrument must be user friendly, not too long and not complicated. Fourth, the time and effort needed to complete the task must be limited. Finally, the accessibility and usability of the instrument should also be a priority, in particular with regards to font size, layout, language and time taken to complete the survey.

\section{Methods}

\subsection{Data collection and participants}

For this validation study, the data originating from the Belgian Ageing Studies (BAS) were used. The BAS, which has been conducted in the Dutch-speaking part of Belgium since 2004, collects information on community-dwelling older people aged 60 and over about their perceptions on various aspects related to the quality of life and living conditions in later life through a highly structured survey. In 2006, the indicators of the CFAI were introduced in the questionnaire. In addition to these questions, descriptive information, such as age, gender, income, marital status and educational level, were obtained. All questions were



Fig. 1. The model of frailty used during the development of the CFAI, based on Gobbens et al. ${ }^{12}$ 
included in a self-administered questionnaire. All questionnaires were entered using Microsoft Access, and the analyses were performed using IBM SPSS 20 and IBM SPSS Amos 18 (IBM, SPSS, Armonk, NY: IBM Corp).

To maximize the response, an interview-design was developed. Through an intensive recruitment campaign, older volunteers who were willing to interview respondents were identified. After training, those volunteers invited their assigned persons to participate, handed over the self-administered questionnaire and provided help when needed. When the respondents refused or were hampered to fill-in the questionnaire, the volunteers received replacement addresses in the same quota category to obtain the intended sample size. The respondents were free to participate, and their anonymity was guaranteed. The respondents were assured of their right to refuse to answer and of the privacy of their responses. A more complete description of the interview-design can be found in Verté et al. ${ }^{18}$ Since the project started, older respondents living in 142 municipalities have been interviewed. In each municipality, addresses were randomly selected from population registries. The sample was stratified, using quotas for gender and age (60-69, 70-79 and $80+$ years) to ensure that the sample matched the makeup of the underlying population in the community. This type of sampling ensured that the $80+$ age group was adequately represented. The sampling fraction depended on the size of the municipality and varied between $N=182$ and $N=1592$, and the first response rate was between 65 and $85 \%$.

Data screening of this sample (with CFAI indicators, $N=54,243$ ) to identify possible response patterns and outliers and missing data analysis were performed. Respondents who presented questionable response patterns or did not respond to at least one of the 31 indicators were withdrawn, resulting in a final sample of 33,629 respondents, which represents $62 \%$ of the original sample.

\subsection{Measures and statistical strategy}

\subsubsection{Measures}

The CFAI captures frailty on 4 domains: physical, psychological, social and environmental. For the "physical domain of frailty" in the CFAI, limitations in physical activities because of health problems were included, which contrasts with Gobbens et $a{ }^{5}{ }^{5}$ who used more biomedical indicators such as nutrition, mobility, physical activity, strength, endurance, balance and sensory functions. The index of general physical health from the 'MOS Short-form General Health Survey' ${ }^{19}$ was used for this purpose. The participants were asked to indicate how long (not at all, 3 months or less or more than 3 months) they had been hampered by their health status in performing the following activities: "Very demanding activities like lifting up heavy objects', 'Less demanding activities like carrying shopping bags', 'Walking up a hill/stairs', 'Bending or lifting', 'Going for a walk' and 'Activities of daily living like eating, dressing or taking a shower'. As mentioned above, by introducing the health measurement instead of diseases or limitations, the negative stereotype that associates aging with disease was eliminated.

For the "psychological domain of frailty" in the CFAI, two measurements were used. First, a 6 item mood-disorder index was used. Research has shown that even minor depressive symptoms that do not meet the diagnostic criteria for depression are associated with the increased use of health services ${ }^{20,21}$ and increased mortality. ${ }^{22-24}$ More than $10 \%$ of older adults seen in a primary care setting should suffer from minor or major depressive disorders, ${ }^{25}$ making it an important issue for detection. ${ }^{26}$ As depression must be evaluated by clinicians, a mood-disorder index to detect distress was used.

The participants were asked to what extent they agree with items related to mood-disorders: 'Troubles with sleeping', 'Feeling unhappy', 'Losing self-confidence', 'Unable to cope with problems', 'Feeling pressure' and 'Feeling worth nothing anymore'. Each item ranged on a 5-point Likert scale from completely disagree (1) to completely agree (5), with higher scores reflecting stronger psychological problems. Second, as mentioned above, frailty was associated with emotional problems by the older persons themselves. ${ }^{10}$ Therefore, these were assessed using 3 propositions of the shortened Loneliness Scale ${ }^{27}$ measuring emotional problems. These propositions were the following: 'I experience a general sense of emptiness', 'I miss having people around me' and 'I often feel rejected'. All propositions ranged on a 5-point Likert scale from completely disagree (1) to completely agree (5), with higher scores reflecting more severe problems.

The "social domain of frailty" included two measurements. First, similar to Gobbens, ${ }^{5}$ social loneliness and social support were included but operationalized differently. Social loneliness was measured through 3 propositions of the shortened Loneliness Scale. ${ }^{27}$ Those propositions were the following: 'There are plenty of people I can lean on when I have problems', 'There are many people I can trust completely' and 'There are enough people I feel close to'. Prior to the analysis, these items were negatively recoded. Furthermore, to obtain an insight into the social support, the participants were asked which of the following persons they could rely on for help if necessary. Based on an exploratory factor analysis with Varimax rotation, the members of the respondents' social network were classified into 3 groups. Social Support Network 1 consisted of partner, son and daughter-in-law. Daughter, son-inlaw and grandchildren were classified in Social Support Network 2, while brother or sister (-in-law), family, neighbors and friends were categorized in Social Support network 3. For each indicator the number of persons the participants could rely on was counted. Afterward, these scores were recoded, with higher scores referring to a decreased network.

Finally, the "environmental domain" consisted of propositions regarding the push factors of the respondent's actual housing and environmental conditions. Push factors ${ }^{28}$ refer to the conditions of a physically inadequate environment, threatening the mobility of aging individuals due to a lack of comfort. To capture these push factors, the following indicators were used: 'My house is in a bad condition', 'I have to walk stairs before entering my house', 'The thresholds are too high both inside and outside my house', 'There are stairs in my house', 'I have to walk up stairs to go to the toilet', 'My house is not comfortable', 'It is difficult to heath my house', 'There is insufficient comfort in my house', 'I do not like the neighborhood' and 'The distance to facilities is too far'. All items could be scored on a 5-point Likert scale, ranging from strongly disagree to strongly agree, with higher scores demonstrating more housing and environmental problems. With the thirty-one indicators mentioned above, the CFAI instrument was constructed (see Fig. 2).

\subsubsection{Statistical strategy}

To determine the construct validity of the CFAI by confirmatory factor analysis, the data were screened for outliers, response patterns, missing data and sampling adequacy. Then, an exploratory factor analysis was conducted to explore the underlying theoretical structure. Third, to assess construct validity of the different measurements, first order confirmatory factor analyses were performed. Fourth, all indicators were introduced in the theoretical model (see Fig. 2), and a second-order confirmatory factor analysis was used to evaluate whether the model fits the data well. All confirmatory factor analyses were performed in IBM SPSS Amos 18.0 (Arbuckle 1983-2009).

To evaluate whether the theoretical model fit the data, different types of fit indices were reported. Working with a large sample set 


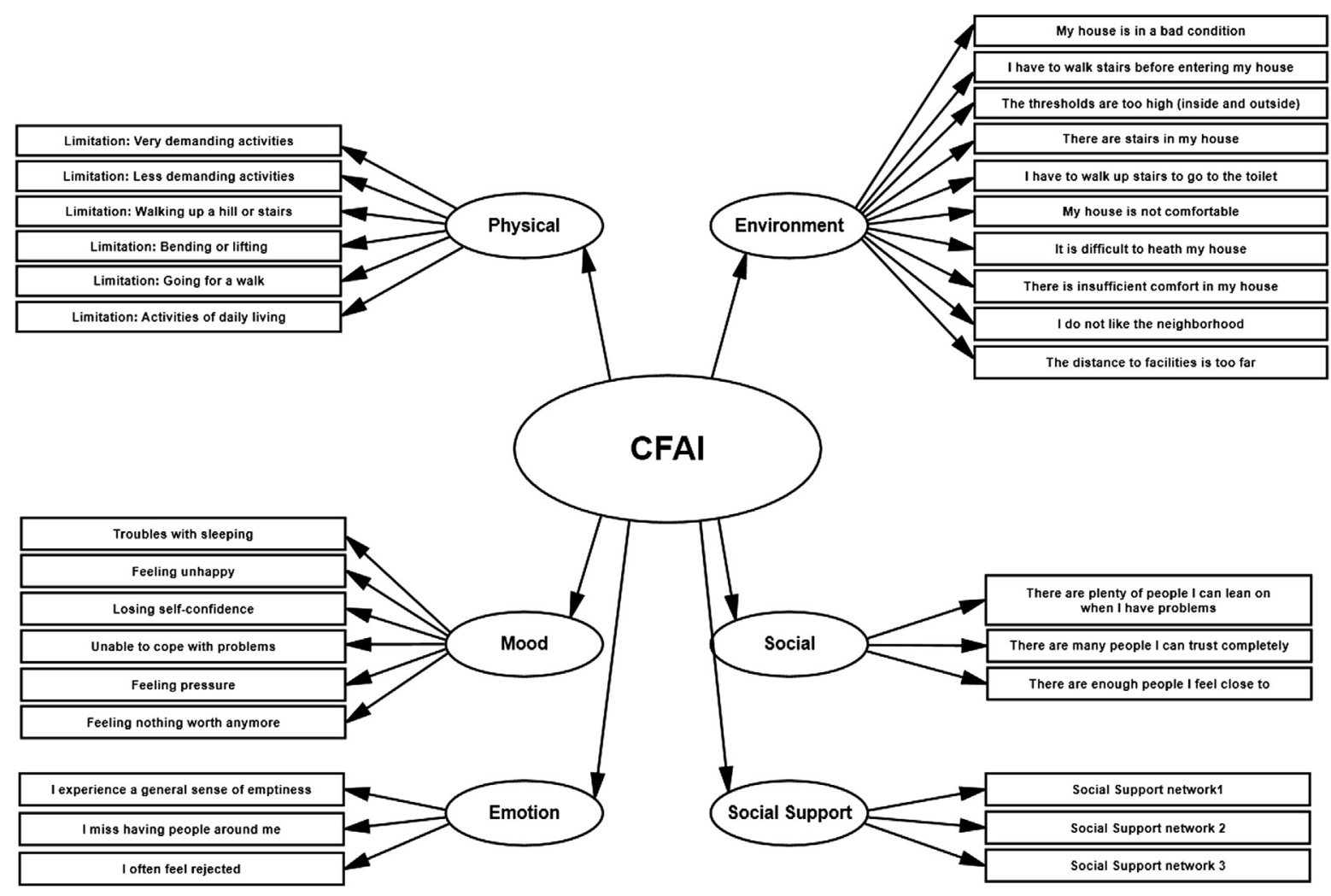

Fig. 2. The theoretical Comprehensive Frailty Assessment Instrument.

requires attention to the effects of sample size. Therefore, fit indices were chosen that are insensitive to sample size: the Root Mean Square Error of Approximation (RMSEA), the Comparative Fit Index (CFI) and the Tucker-Lewis index (TLI). First, the RMSEA is a widely used and recommended index. ${ }^{29}$ Models with RMSEA values less than .05 indicate a good fit, and values as high as .08 represent a reasonable fit. ${ }^{30-32}$ RMSEA is insensitive to sample size. ${ }^{29,33}$ In addition to the RMSEA, the lower boundary (RMSEA-LO) and upper boundary (RMSEA-HI) of a two-sided $90 \%$ confidence interval were calculated. Second, the CFI assesses the fit to a null model using non-centrality parameters and ranges from 0 to 1 , with values of .9 or greater indicating a good fit. ${ }^{34}$ The CFI is also insensitive to sample size. ${ }^{33}$ Third, the TLI compares a proposed model's fit to a nested baseline or null model and measures parsimony by assessing the degrees of freedom from the proposed model to the degrees of freedom of the null model. It is resilient against sample size variations. ${ }^{33}$ In the past, the cut-off for the TLI was set at .90 , but recently there appears to be consensus that this value should increase to $.95 .^{35}$ Widely used fit indices such as the $\chi^{2}$ test, goodness-of-fit index (GFI), adjusted goodness-of-fit (AGFI) and normed fit index (NFI) ${ }^{36}$ tend to be influenced by sample size ${ }^{37}$ and were therefore not used as fit indices herein. Finally, internal consistency was assessed through Cronbach's $\alpha$ coefficients. A scale was considered adequate if the alpha value was at least $.50 .^{38}$

\section{Results}

\subsection{Preliminary analysis}

The sample was screened for items with limited discriminating characteristics or with high positive or negative kurtosis and skewness values. As no such items were found, all items could be included. Furthermore, no problems with multicollinearity were detected. Finally, the 'Kaiser-Meyer-Olkin measure of sampling adequacy' (.884) was considered to be good, and Bartlett's test of sphericity was significant $(p<.001)$, indicating that all items could be included and that the factor analysis was appropriate. ${ }^{39}$

\subsection{Respondents characteristics}

The age range of the respondents was 60-107 years, with a median of 70 years. Additionally, $51.0 \%$ of the respondents were female, $39.9 \%$ had no or only primary education, and $18.9 \%$ had an income less than $€ 1000$. Regarding the marital status, $71.8 \%$ of the respondents were married, $19.9 \%$ were widowed, and $3.2 \%$ were divorced.

\subsection{CFAI: testing the measurements}

An exploratory factor analysis was performed on the different measurements of the CFAI. Exploratory factor analysis is a method used to uncover the underlying structure of a set of variables and is commonly used in scale development. As shown in Table 1, all factor-loadings were greater than .30 . Next, a reliability analysis was used to evaluate the internal consistency and the total explained variance. The reliability ranged from mediocre for the social support network (Cronbach's $\alpha=.527$ ) to high for the physical limitations (Cronbach's $\alpha=.891$ ). The total explained variance ranged from $34.5 \%$ to $70 \%$ (see Table 1 ).

As the results of the exploratory factor analysis were shown to be satisfactory, a confirmatory factor analysis was performed on all measurements. Confirmatory factor analysis is used to test whether the data fit a hypothesized measurement model. The results of this confirmatory factor analysis are shown in Table 2. For the 


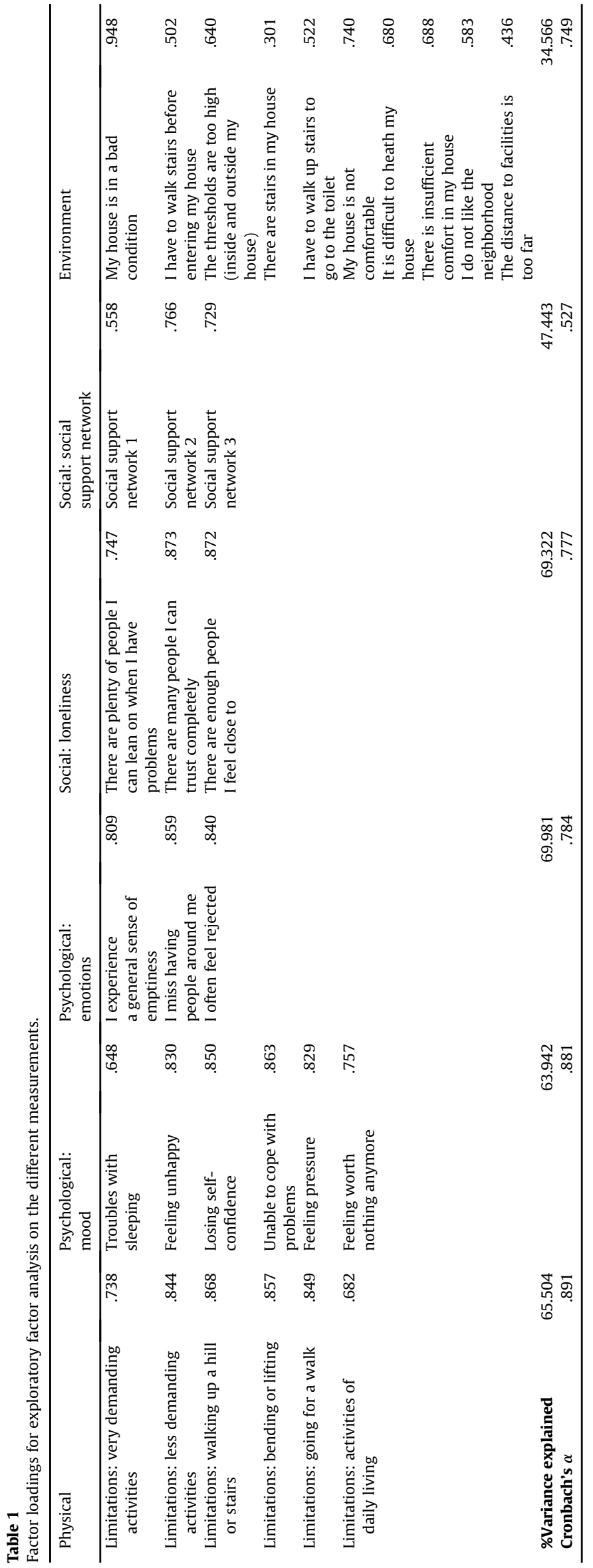

Table 2

Results of the confirmatory factor analysis on the different measurements.

\begin{tabular}{llllll}
\hline & RMSEA & RMSEA-LO & RMSEA-HI & CFI & TLI \\
\hline Physical & .096 & .090 & .103 & .992 & .976 \\
Psychological: mood & .080 & .076 & .074 & .989 & .977 \\
Psychological: emotions & .091 & .082 & .100 & .991 & .972 \\
$\begin{array}{l}\text { Social: loneliness } \\
\text { Social: social support }\end{array}$ & .026 & .017 & .035 & .999 & .998 \\
$\quad$ network & .046 & .037 & .055 & .985 & .955 \\
Environment & .047 & .013 & .021 & .999 & .998 \\
\hline
\end{tabular}

RMSEA = root mean square error of approximation with $90 \%$ confidence interval (RMSEA-LO, RMSEA-HI); CFI = comparative fit index; TLI = Tucker-Lewis index.

limitations in physical health, items 1 and 6 needed to be deleted to obtain acceptable fit indices. For the same reason, the first item from mood-disorders as well as items 2-5 and item 10 from the environmental indicators were deleted. The emotional, social and social support measurements were assessed in the CFA by implementing one additional constraint and showed good model fit indices without deleting any indicators.

\subsection{CFAI: testing the instrument}

The CFAI was tested using a second-order confirmatory factor analysis. In a second-order factor analysis, all measurements are simultaneously introduced. The starting point was the theoretical model (see Fig. 2). Items with low factor loadings were subsequently deleted based on significance to improve the model fit. As a result, eight models were developed. The fit indices of the eight models and the deleted indicators are presented in Table 3.

The first 5 adaptations were performed due to low factor loadings between the latent variable environment and its indicators. The items 'Troubles with sleeping', 'Limitations: Activities of daily living' and 'Limitations: Very demanding activities' were deleted due to large covariances in their errors. Although Social Support network 3 showed a relatively low factor loading on the network (.32), it was retained in the model. Deleting this indicator decreased the factor loading between the CFAI and Social Support from .35 to an unacceptable .27. As a result, a definitive instrument (see Fig. 3) was established with a total of twenty-three indicators. The model showed good to excellent fit indices: RMSEA $=.032(90 \%$ interval $=.032-.033), \mathrm{CFI}=.974$ and $\mathrm{TLI}=.970$. These results

Table 3

Deleted indicators during the development of the CFAI.

\begin{tabular}{|c|c|c|c|c|c|c|}
\hline & RMSEA & RMSEA-LO & RMSEA-HI & CFI & TLI & Deleted item \\
\hline Model 0 & .043 & .043 & .043 & .930 & .924 & \\
\hline Model 1 & .043 & .043 & .044 & .934 & .928 & $\begin{array}{l}\text { There are stairs in my } \\
\text { house }\end{array}$ \\
\hline Model 2 & .044 & .043 & .044 & .935 & .929 & $\begin{array}{l}\text { The distance to facilities } \\
\text { is too far }\end{array}$ \\
\hline Model 3 & .040 & .039 & .040 & .950 & .945 & $\begin{array}{l}\text { I have to walk stairs } \\
\text { before entering my } \\
\text { house }\end{array}$ \\
\hline Model 4 & .039 & .039 & .040 & .953 & .949 & $\begin{array}{l}\text { I have to walk up stairs } \\
\text { to go to the toilet }\end{array}$ \\
\hline Model 5 & .040 & .039 & .040 & .955 & .950 & $\begin{array}{l}\text { The thresholds are too } \\
\text { high (inside and outside } \\
\text { my house) }\end{array}$ \\
\hline Model 6 & .037 & .036 & .038 & .963 & .958 & $\begin{array}{l}\text { Limitations: activities } \\
\text { of daily living }\end{array}$ \\
\hline Model 7 & .035 & .034 & .035 & .968 & .964 & Troubles with sleeping \\
\hline Model 8 & .032 & .032 & .033 & .974 & .970 & $\begin{array}{l}\text { Limitations: very } \\
\text { demanding activities }\end{array}$ \\
\hline
\end{tabular}

RMSEA = Root Mean Square Error of Approximation with 90\% confidence interval (RMSEA-LO, RMSEA-HI); CFI = Comparative Fit Index; TLI = Tucker-Lewis index. 


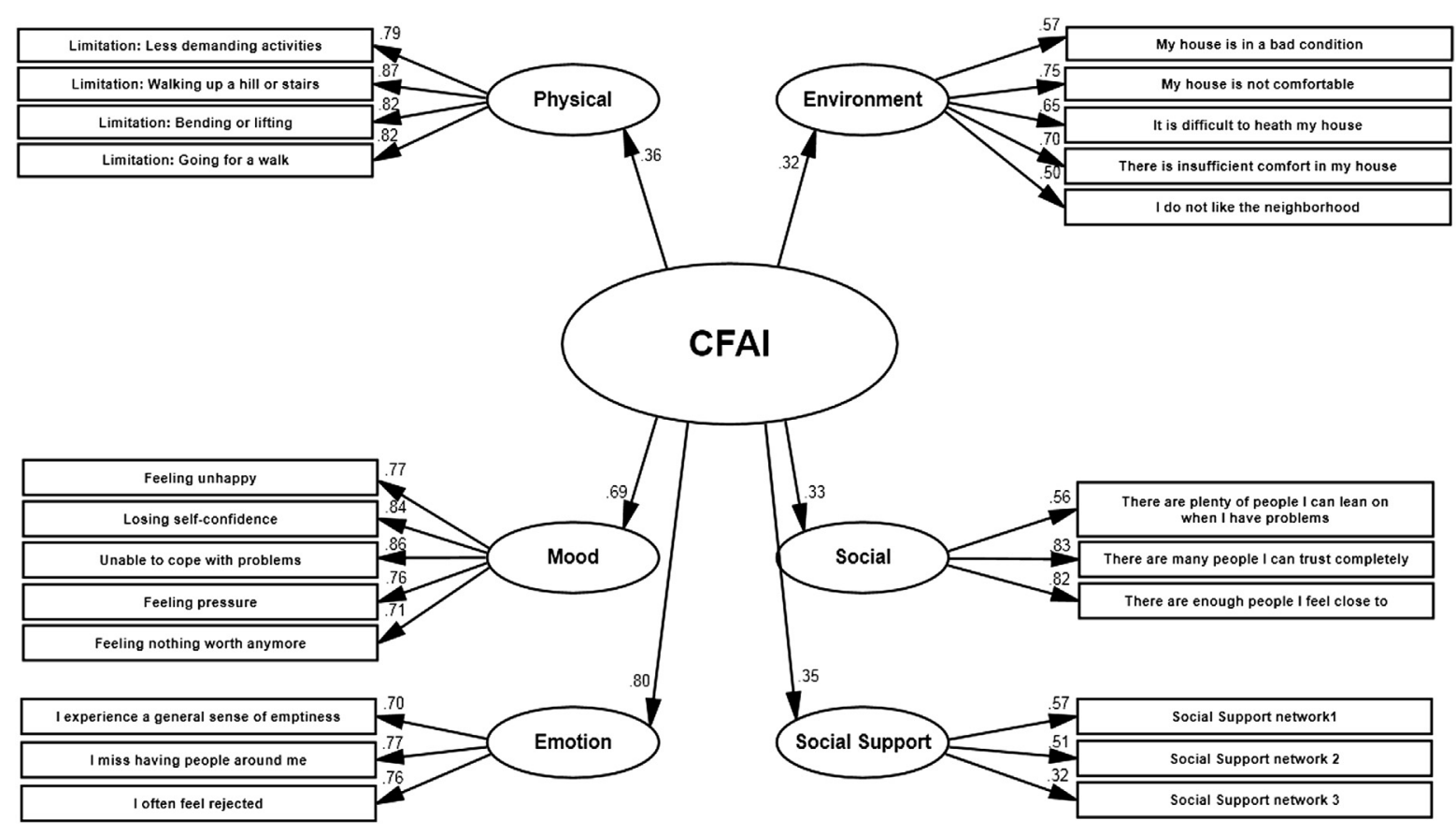

Fig. 3. The finalized Comprehensive Frailty Assessment Instrument.

indicate that the model fits the data well. Emotions contributed most to frailty (.80), followed by mood-disorders (.69) and limitations in physical health (.36). Social (.33), Social Support (.35) and Environment (.32) all contributed to frailty. Finally, we examined the reliability of the CFAI. The Cronbach's $\alpha$ of the entire scale was .812 , explaining $63.6 \%$ of the variance in frailty.

\section{Discussion}

The focus of the present study was to develop and assess the psychometric properties of a new multidimensional frailty instrument including four domains of frailty; physical, psychological, social and environmental. This instrument, the CFAI, contains twenty-three indicators and demonstrates a high overall internal consistency and high consistency of its scales, thus supporting the validity and reliability of the instrument and highlighting to the multidimensionality of frailty as described by Markle-Reid and Browne. ${ }^{13}$ The CFAI has been proven to be internally consistent, with a Cronbach's $\alpha$ of .812 that explains $63.6 \%$ of the variance in frailty.

This study provides evidence for the contribution of all four domains to frailty. The psychological domain added the most to frailty. These results confirm what several studies have already addressed, ${ }^{13,40-42}$ that frailty is more than just a purely physical phenomenon. Although the contribution of environmental indicators to frailty is rather moderate, it contributes almost as much as the social indicators or physical indicators. Environmental indicators include the bad condition of the house, the house being uncomfortable, problems with heating the house and aversion against the neighborhood. These factors are in line with Walker, ${ }^{14}$ Costa-Font ${ }^{8}$ and Wahl, ${ }^{15}$ who all highlighted the importance of the spatial context and environmental resources on which an individual depends when aging. As suggested by Crooks, ${ }^{7}$ social support also contributed to frailty.

Some items for the physical, psychological and environmental domains did not fit as anticipated in the theoretical model. To the best of our knowledge, there has been no prior research regarding these items. As a consequence, possible explanations for the non-fit of these items were sought. For the physical limitations, very demanding activities such as lifting heavy objects and the activities of daily living were not included in the instrument. For the very demanding activities, a possible explanation may be that only community-dwelling older persons were interviewed. Indeed, people with severe physical problems are often institutionalized and were thus not included in our sample. Activities of daily living were also not included in the CFAI. Once again, this omission can be a consequence of the inclusion criteria of the sample. Another explanation is that for activities of daily living, substitute services are available. As Belgium has a well-developed network of community nurses, older people receiving support for their activities of daily living may not feel frail anymore. A longitudinal study for this issue could confirm this hypothesis.

For the mood-disorders, trouble with sleeping was not included. In the environmental assessment, five indicators were not included: 'I have to walk stairs before entering my house', 'The thresholds are too high both inside and outside my house', 'There are stairs in my house', 'I have to walk up stairs to go to the toilet' and 'The distance to facilities is too far'. All of the excluded indicators were connected to mobility in and around the house. A possible explanation for the deletion of these items in the secondorder confirmatory factor analysis can be that those mobility problems are assessed by items 2-5 from the physical domain. Indeed, when someone indicated having problems with less demanding activities such as carrying shopping bags or going for a walk, he or she also had problems with the distance to facilities being too far.

The CFAI is developed as a screening instrument for assessing frailty in the community and does not rely on clinical judgments by high skilled caregivers. Indeed, the CFAI can be filled in by the older person him/herself or his/her carer or if this is no longer possible, also by lower skilled caregivers. The great advantage of the CFAI is that it is a fast, easy and inexpensive assessment tool for use in the community. Most frailty instruments are based on clinical judgments and are therefore not directly applicable in community care. 
Moreover, as the underlying structure of the CFAI demonstrates the multidisciplinary nature of frailty, the use of the CFAI can stimulate nurses and other community healthcare providers toward a more holistic approach to frailty and can guide them toward taking the appropriate interventions to prevent adverse outcomes such as disabilities or hospitalization.

\subsection{Strengths and limitations}

The CFAI has some advantages over most other frailty instruments. The scale is not too long. It comprises 23 items and captures physical, psychological, social and environmental aspects of frailty, thereby changing the vision toward frailty as proposed by Markle-Reid, ${ }^{13} \operatorname{Hogan}^{43}$ and Levers et al. ${ }^{44}$

The major strength of this study is the large sample size upon which our validation results are based. The analyses were performed on a large dataset of the Belgian Ageing Studies, with a better size and representativeness than most studies capturing frailty in the aged. Moreover, the dataset was of a high quality with a stratified representative sample (for age and gender) of 33,629 community-dwelling older persons.

Finally, this study has contributed to our knowledge of frailty with respect to emotional loneliness, social support and the environmental domain, thereby extending the concept of frailty toward a more holistic measure.

Despite the strengths of the present study, there are some limitations. A first shortcoming might be that only Dutch-speaking Belgians have participated. Cross-validating the CFAI by including international samples would enrich the external validity of this measurement instrument. Second, validating the scale against a gold standard would strengthen the evidence that the CFAI actually captures frailty. Third, although the overall internal consistency (Cronbach's $\alpha=.81$ ) and explained variance (63.58\%) are high, some factor loadings proved to be mediocre. Future research might offer further insights here.

\subsection{Implications and directions for further research}

This study provides support for using the CFAI as a measure of frailty in community-dwelling older persons. As mentioned above, further research should include the validation of the CFAI against a gold standard. To obtain more insight into frailty-related problems, research should also focus on its individual and contextual determinants. Further research could also focus on the predictive validity of the CFAI for adverse outcomes (see Fig. 1) and address the question of to what extent the environmental aspects of frailty predict these outcomes.

\section{Conflict of interest}

None of the authors have any conflicting interests to report.

\section{Ethical approval}

This study was conducted according to the ethical guidelines laid down in the Declaration of Helsinki. Because no experiments on humans were conducted, no ethics committee was involved.

\section{Acknowledgments}

The Research fund of the University College Ghent is acknowledged for its financial contribution.

\section{References}

1. Eurostat. Europe in Figures-Eurostat Yearbook 2011; 2011.

2. Fried LP, Ferruci L, Darer J, Williamson JD, Anderson G. Untangling the concepts of disability, frailty, and comorbidity: implications for improved targeting and care. J Gerontol A Biol Sci Med Sci. 2004;59:255-263.

3. Puts M, Lips P, Deeg D. Static and dynamic measures of frailty predicted decline in performance-based and self-reported physical functioning. J Clin Epidemiol. 2005;58:1188-1198.

4. Rolfson DB, Majumdar SR, Tsuyuki RT, Tahir A, Rockwood K. Validity and reliability of the Edmonton Frail Scale. Age Ageing. 2006;35:526-529.

5. Gobbens RJ, van Assen MA, Luijkx KG, Wijnen-Sponselee MT, Schols JM. The Tilburg Frailty Indicator: psychometric properties. J Am Med Dir Assoc. 2010;11: 344-355.

6. Schröder-Butterfill E, Marianti R. A framework for understanding old-age vulnerabilities. Ageing Soc. 2006;26:9-35.

7. Crooks D. Development and Testing of the Elderly Social Vulnerability Index (ESVI): A Composite Indicator to Measure Social Vulnerability in the Jamaican Elderly Population. Miami: Florida International University; 2009.

8. Costa-Font J, Elvira D, Mascarilla-Miro O. 'Ageing in Place'? Exploring elderly people's housing preferences in Spain. Urban Stud. 2009;46:295-316.

9. Grenier A. Constructions of frailty in the English language, care practice and the lived experience. Ageing Soc. 2007;27:425-444.

10. Grenier A, Hanley J. Older women and 'Frailty': aged, gendered and embodied resistance. Curr Sociol. 2007;55:211-228.

11. Bravell M, Westerlind B, Midlöv P, et al. How to assess frailty and the need for care? Report from the Study of Health and Drugs in the Elderly (SHADES) in community dwellings in Sweden. Arch Gerontol Geriatr. 2011;53:40-45.

12. Gobbens RJ, Luijkx KG, Wijnen-Sponselee MT, Schols JM. Toward a conceptual definition of frail community dwelling older people. Nurs Outlook. 2010;58: $76-86$.

13. Markle-Reid M, Brown G. Conceptualizations of frailty in relation to older adults. J Adv Nurs. 2003;44:58-68.

14. Walker A. A European perspective on quality of life in old age. Eur J Ageing. 2005;2:2-12.

15. Wahl H-W, Schilling O, Oswald F, Iwarsson S. The home environment and quality of life-related outcomes in advanced old age: findings of the ENABLEAGE project. Eur J Ageing. 2009;6:101-111.

16. Buffel T, Phillipson C, Scharf T. Ageing in urban environments: developing agefriendly cities. Crit Soc Pol; 2012; http://dx.doi.org/10.1177/0261018311430457. Published online before print May 22, 2012.

17. Robertson ANN. Beyond apocalyptic demography: towards a moral economy of interdependence. Ageing Soc. 1997;17:425-446.

18. Verté D, De Witte N, De Donder L. Schaakmat of aan zet. Monitor voor lokaal ouderenbeleid in Vlaanderen. [Guidelines for Local Policy Towards Older People in Flanders]. Brugge: Vanden Broele; 2007 [In Dutch].

19. Kempen GI. Het meten van de gezondheidstoestand van ouderen; een toepassing van de Nederlandse versie van de MOS-schaal. [Measuring health status in the aged. An application of the Dutch version of the MOS]. Tijdschr Gerontol Geriatr; 1992;132-140 [in Dutch].

20. Johnson J, Weissman MM, Klerman GL. Service utilization and social morbidity associated with depressive symptoms in the community. JAMA. 1992;267: $1478-1483$.

21. Unutzer J, Patrick DL, Simon G, et al. Depressive symptoms and the cost of health services in HMO patients aged 65 years and older. A 4-year prospective study. JAMA. 1997;277:1618-1623.

22. Whooley MA, Browner WS. Association between depressive symptoms and mortality in older women. Study of Osteoporotic Fractures Research Group. Arch Intern Med. 1998;158:2129-2135.

23. Penninx BW, Guralnik JM, Ferrucci L, Simonsick EM, Deeg DJ, Wallace RB. Depressive symptoms and physical decline in community-dwelling older persons. JAMA. 1998;279:1720-1726.

24. Takeida K, Nishi M, Miyake H. Zung's depression scale as a predictor of death in elderly people: a cohort study in Hokkaido, Japan. J Epidemiol. 1999;9: 240-244.

25. Lyness JM, Yu Q Tang W, Tu X, Conwell Y, et al. Risks for depression onset in primary care elderly patients: potential targets for preventive interventions. Am J Psychiatry. 2009;166:1375-1383.

26. Park M, Unutzer J. Geriatric depression in primary care. Psychiatr Clin North Am. 2011;34:469-487. ix-x.

27. de Jong-Gierveld J, van Tilburg T. De ingekorte schaal voor algemene, emotionele en sociale eenzaamheid. [The shortened scale for overall, emotional and social loneliness]. Tijdschr Gerontol Geriatr. 2008;39:4-15 [in Dutch].

28. Stimson RJ, McCrea R. A push-pull framework for modelling the relocation of retirees to a retirement village: the Australian experience. Environ Plann. 2004;36:1451-1470.

29. Brown T. Confirmatory Factor Analysis for Applied Research. New York, London: The Guilford Press; 2006.

30. Browne MW, Cudeck R. Alternative ways of assessing model fit. In: Bollen KA, Long JS, eds. Testing Structural Equation Models. Newbury Park, CA: Sage; 1993: $136-162$.

31. Hair J, Black W, Babin B, Anderson RE. Multivariate Data Analysis. Upper Saddle River, New Jersey: Prentice Hall; 2007. 
32. Browne MW, Cudeck R. Alternative ways of assessing model fit. Socio Meth Res. 1992;21:230-258.

33. Hoe S. Issues and procedures in adopting structural equation modeling technique. J Appl Quant Meth. 2008;3:76-83.

34. Bentler PM. Comparative fit indexes in structural model. Psychol Bull. 1988; $107: 238-246$.

35. Hu LT, Bentler PM. Cutoff criteria for fit indexes in covariance structure analysis: conventional criteria versus new alternatives. Struct Equ Modeling. 1999;6:1-55.

36. Hu L-T, Bentler PM. Evaluating model fit. In: Hoyle RH, ed. Structural Equation Modeling: Concepts, Issues and Applications. Thousand Oaks, CA: Sage; 1995: 76-99.

37. Tanguma J. Effects of sample size on the distribution of selected fit indices: a graphical approach. Educ Psychol Meas. 2001;61:759-776.

38. Bowling A. Research Methods in Health. Berkshire: Open University Press McGraw-Hill International; 2009.
39. Field A. Discovering Statistics Using SPSS. ed. Los Angeles, London, New Delhi, Singapore, Washington DC: Sage; 2009.

40. Gobbens RJ, Luijkx KG, Wijnen-Sponselee MT, Schols JM. Towards an integral conceptual model of frailty. J Nutr Health Aging. 2010;14:175181.

41. Grundy E. Ageing and vulnerable elderly people: European perspectives. Ageing Soc; 2006;105-134

42. Walston J, Hadley EC, Ferrucci L, et al. Research agenda for frailty in older adults: toward a better understanding of physiology and etiology: summary from the American Geriatrics Society/National Institute on Aging Research Conference on Frailty in Older Adults. J Am Geriatr Soc. 2006;54: 991-1001.

43. Hogan DB, MacKnight C, Bergman H. Models, definitions, and criteria of frailty. Aging Clin Exp Res. 2003;15:1-29.

44. Levers M-J, Estabrooks CA, Ross Kerr JC. Factors contributing to frailty: literature review. J Adv Nurs. 2006;56:282-291. 